\begin{tabular}{l|l}
\hline T A B L E & Procedures \\
Procedure & Percentage of Total Procedures \\
\hline Sebaceous cysts & 29 \\
\hline IUD & 10 \\
\hline Knee injection & 8 \\
\hline Nexplanon & 8 \\
\hline EMB & 10 \\
\hline Trigger finger & 3 \\
\hline Plantar fasciitis injection & 1 \\
\hline Lipoma & 3 \\
\hline Ingrown toenail & 4 \\
\hline Other skin lesions & 24 \\
\hline
\end{tabular}

Abbreviations: IUD, intrauterine device; EMB, endometrial biopsy.

staffed by 1 resident and 1 attending who could directly observe all procedures and assess resident competency.

\section{Outcomes to Date}

The procedure clinic is well utilized by both the internal medicine and family medicine departments, and is fully booked each week. The procedures scheduled over a 3month period are listed in the T A B L E.

\section{Conclusions}

Benefits for resident education include improving the quality of procedural training through increased and consistent exposure to procedures and evaluation of competency.

\section{Kathleen Dor, MD}

Program Director, Kaiser Woodland Hills Family Medicine Residency

Corresponding author: Kathleen Dor, MD, Kaiser Woodland Hills Family Medicine Residency, 5601 De Soto Ave, Woodland Hills, CA 91367, 818.719.2688, Kathleen.T.Dor@kp.org

\title{
New Ideas
}

\section{How Bodies Learn: A Brief Intervention Using Dance and Dialogue}

Elissa foster, PhD

Nicole Defenbaugh, PhD

\section{Setting}

Although the practice of medicine is inextricably involved with the body, medicine's inherent emphasis on cognition and mental processing means the physician's body is largely ignored as a site of learning. One consequence of this disembodiment is that residents' capacity to monitor their behaviors is compromised. In addition, the adult learning paradigm that dominates current approaches to innovation in medical education expects learners to be self-aware and actively reflect on their learning processes. Many residents have little experience engaging in such reflection. The brief intervention described in this article addresses the problem of "disembodied learning" for physicians in training with the following objectives:

1. Recognize which learning strategies residents are likely to enact in response to new stimuli (eg, new clinical environment, new rotation, or new levels of responsibility).

2. Analyze and articulate how medical education impacts and changes resident bodies as they learn how to perform competently as physicians.
3. Practice leadership and team building through effective communication.

\section{Intervention}

The intervention consists of residents choreographing and performing a dance (think Electric Slide, not Swan Lake) as a group, followed by a facilitated dialogue linking the activity to embodied learning. The duration of the exercise is 60 to 90 minutes; with 45 to 60 minutes allocated to the dance portion, and 15 to 30 minutes for the dialogue.

This activity was designed for a cohort of family medicine residents halfway through their internship year and could be run with a cohort from any specialty, with the expectation that the dialogue portion of the activity will differ depending on the residents' experiences. The group should be around 6 to 10 dancers (everyone in the room must dance to the best of their ability - no spectators). Larger groups can be split provided there is sufficient space.

The exercise requires room for the group to move, a stereo, a contemporary song (with a brisk, walking-pace beat), 


\begin{tabular}{|l|l} 
Guiding Questions for the Facilitator & Typical Responses From Participants \\
\hline How did you learn the dance? & $\begin{array}{l}\text { "Fake it 'til you make it." Repetition. Following someone else. Staying in the back to practice. Made up } \\
\text { memorable names for the steps (eg, "the sprinkler"). }\end{array}$ \\
\hline $\begin{array}{l}\text { How does this activity relate to the } \\
\text { experience of learning medicine and } \\
\text { interacting with others? }\end{array}$ & $\begin{array}{l}\text { Every time I go to a new rotation or a new clinic it's like I have to start again. There is lots of repetition. It } \\
\text { helps to follow someone who knows what they are doing. Go through the motions until you know what } \\
\text { you're doing. }\end{array}$ \\
\hline $\begin{array}{l}\text { What is your body learning as you learn } \\
\text { medicine? }\end{array}$ & $\begin{array}{l}\text { (Silence.) How to metabolize caffeine quickly. How to walk for miles. How to work with no sleep. How to eat } \\
\text { quickly. How to carry my computer, my phone, my pager, and my water in my lab coat pockets. How to } \\
\text { endure. How to do without. How to be uncomfortable and not let anyone know. }\end{array}$ \\
\hline $\begin{array}{l}\text { What positive things is your body learning? } \\
\text { How do you feel about your body as a result } \\
\text { of this activity? }\end{array}$ & $\begin{array}{l}\text { To listen and hear-hearts, lungs, bellies. To notice and see things I couldn't before. To feel-skin, muscle, } \\
\text { bones, organs. To perform procedures. }\end{array}$ \\
\hline
\end{tabular}

and a confident facilitator to keep the group moving. The facilitator must be able to (1) count to the beat of the music, (2) keep the group moving by assisting with the addition of new steps and practicing as described below, and (3) facilitate open dialogue centered on the residents' experiences.

\section{Instructions}

Dance (1) Announce that the goal is to choreograph, learn, and perform a dance as a group within the next hour. (2) Each member of the group devises movement for 8 counts; count out the time for them while the music is playing. (3) Build the dance; each person teaches their 8 counts; when the group feels comfortable, add the next 8 counts. Practice from the beginning as often as necessary. Continue until all the steps have been added. (4) If time permits, divide the group into 2 and have each half "perform" the dance for the others. (5) Offer a 5-minute break to rest the body before the discussion.

Dialogue Use the guiding questions in the left column of the T A B L E to begin the conversation. Be prepared to follow the learners' lead.

\section{Outcomes to Date}

This activity has been run annually with 4 cohorts of family medicine interns, including, on average, 6 residents, a facilitator, the program director, and 1 or 2 clinical faculty members. The setting was a required 2-day retreat, with the dance activity scheduled after lunch on the first day. The sample responses from the dialogue portion of the activity speak to its success in raising residents' awareness of their bodies' learning in the course of clinical training. For different specialties, the dialogue may reveal other insights (eg, surgery residents may focus more on physical skills training and their bodies' condition during lengthy procedures). The dance and dialogue have resulted in increased awareness of self and others, in addition to enhancing the cohesion of the group by serving as a shared memory and focal point for in-group humor, helpful self-deprecation, and appreciation of difference. In the future, it may be beneficial to elicit resident and faculty reflections on its impact both in the short-term and long-term.

\section{Elissa Foster, $\mathrm{PhD}$}

Associate Professor and Program Director for MA in Health Communication, College of Communication, DePaul University

Nicole Defenbaugh, PhD

Director of Medical Education and Program Evaluation, Department of Family Medicine, Lehigh Valley Health Network

Corresponding author: Elissa Foster, PhD, College of Communication, DePaul University, 1 East Jackson Blvd, Chicago, IL 60604, 312.362.8954, commscholar@hotmail.com 